\title{
Currículo e políticas educacionais: A Base Nacional Comum Curricular e o processo de homogeneização curricular
}

\author{
Curriculum and educational policies: The Common National Curriculum Base and the curriculum \\ homogenization process \\ Plan de estudios y políticas educativas: La Base Común del Plan de Estudios Nacional y el proceso \\ de homogeneización del plan de estudios
}

Recebido: 30/03/2021 | Revisado: 09/04/2021 | Aceito: 13/04/2021 | Publicado: 24/04/2021

\author{
Kélli Renata Corrêa de Mattos \\ ORCID: https://orcid.org/0000-0002-4671-3247 \\ Universidade Federal de Santa Maria, Brasil \\ E-mail: kellic.mattos@gmail.com \\ Micheli Bordoli Amestoy \\ ORCID: https://orcid.org/0000-0002-5687-5311 \\ Universidade Federal de Santa Maria, Brasil \\ E-mail: micheliamestoy@gmail.com \\ Luiz Caldeira Brant de Tolentino-Neto \\ ORCID: https://orcid.org/0000-0001-6170-1722 \\ Universidade Federal de Santa Maria, Brasil \\ E-mail: lcaldeira@gmail.com
}

\begin{abstract}
Resumo
Há décadas, discussões sobre um currículo comum tem sido foco das políticas públicas brasileiras. A implementação da Base Nacional Comum Curricular (BNCC) configura um processo de homogeneização do ensino e vem ganhando forma não só a nível nacional, mas, também, estadual e municipal. Esse estudo tem como objetivo apresentar alguns aspectos relevantes da construção do Documento Orientador Curricular de Santa Maria (DOC/SM). Tanto o Referencial Curricular Gaúcho (RCG) do estado do Rio Grande do Sul quanto o DOC/SM foram currículos elaborados à luz da BNCC. Visando a análise do processo de construção curricular no município de Santa Maria/RS, realizou-se um estudo de campo, com observação participante nos encontros e audiências de construção do documento. Constatou-se, por meio da observação, um dilema entre a tentativa de democratização na construção de uma política municipal (DOC/SM) e a necessidade de alinhamento das políticas educacionais à BNCC. Sinalizando, de forma interdependente - as amarras e a padronização - da atual política de currículo nacional.
\end{abstract}

Palavras-chave: Políticas públicas; Currículo municipal; BNCC.

\begin{abstract}
For decades, discussions about a common curriculum have been the focus of Brazilian public policies. The implementation of the National Common Curricular Base (BNCC) is a process of homogenizing teaching and has been taking shape not only at the national level, but also at the state and municipal levels. This study aims to present some relevant aspects of the construction of the Santa Maria Curricular Guiding Document (DOC / SM). Both the Rio Grande do Sul State Referential Curriculum (RCG) and the DOC / SM were curricula prepared in the light of the BNCC. Aiming at the analysis of the curriculum construction process in the municipality of Santa Maria / RS, a field study was carried out, with participant observation in the meetings and hearings of document construction. It was found, through observation, a dilemma between the attempt to democratize the construction of a municipal policy (DOC / SM) and the need to align educational policies with the BNCC. Thus evidencing the moorings and the standardization of the current national curriculum policy.
\end{abstract}

Keywords: Public policy; Municipal curriculum; BNCC.

\section{Resumen}

Durante décadas, las discusiones sobre un currículo común han sido el foco de las políticas públicas brasileñas. La implementación de la Base Curricular Común Nacional (BNCC) es un proceso de homogeneización de la docencia y se ha ido gestando no solo a nivel nacional, sino también a nivel estatal y municipal. Este estudio tiene como objetivo presentar algunos aspectos relevantes de la construcción del Documento Orientador Curricular de Santa María (DOC / SM). Tanto el Currículo Referencial del Estado de Rio Grande do Sul (RCG) como el DOC / SM fueron currículos preparados a la luz del BNCC. Con el objetivo de analizar el proceso de construcción curricular en el municipio de 
Santa María / RS, se realizó un estudio de campo, con observación participante en las reuniones y audiencias de construcción documental. Se encontró, a través de la observación, un dilema entre el intento de democratizar la construcción de una política municipal (DOC / SM) y la necesidad de alinear las políticas educativas con la BNCC. Evidenciando así los amarres y la estandarización de la actual política curricular nacional.

Palabras clave: Políticas públicas; Plan de estudios municipal; BNCC.

\section{Introdução}

As políticas públicas educacionais brasileiras, tiveram significativas mudanças na última década, em especial as curriculares. Dentre essas mudanças, destaca-se a consolidação de uma Base Nacional Comum Curricular (BNCC). Entende-se que a construção de um currículo comum para todo o território nacional, esteja estreitamente relacionada a uma agenda global e as pressões internacionais - com vistas à padronização curricular, mensuração de resultados e interesses mercadológicos definidos (Moreira, 2012).

De acordo com Libâneo (2016) a internacionalização das políticas educacionais é um movimento inserido no contexto da globalização e significa a:

[...] modelação dos sistemas e instituições educacionais conforme expectativas supranacionais definidas pelos organismos internacionais ligados às grandes potências econômicas mundiais, com base em uma agenda globalmente estruturada para a educação, as quais se reproduzem em documentos de políticas educacionais nacionais como diretrizes, programas, projetos de lei, etc. (Libâneo, 2016, p.43).

Um exemplo recente da demarcação da agenda global nas políticas educacionais nacionais foi à repercussão no currículo escolar brasileiro, a partir da adesão do país a Declaração de Incheon (2015), aprovada no Fórum Mundial de Educação, ocorrido na Coréia do Sul, em 2015. O referido evento confiou à UNESCO a liderança e coordenação da Educação 2030, por meio de orientação e apoio técnico no âmbito dos Objetivos de Desenvolvimento Sustentável (ODS) - constituindo a Agenda internacional para a educação até o ano de 2030 (Figura 1).

Figura 1. Os 17 ODS presentes na Agenda 2030.
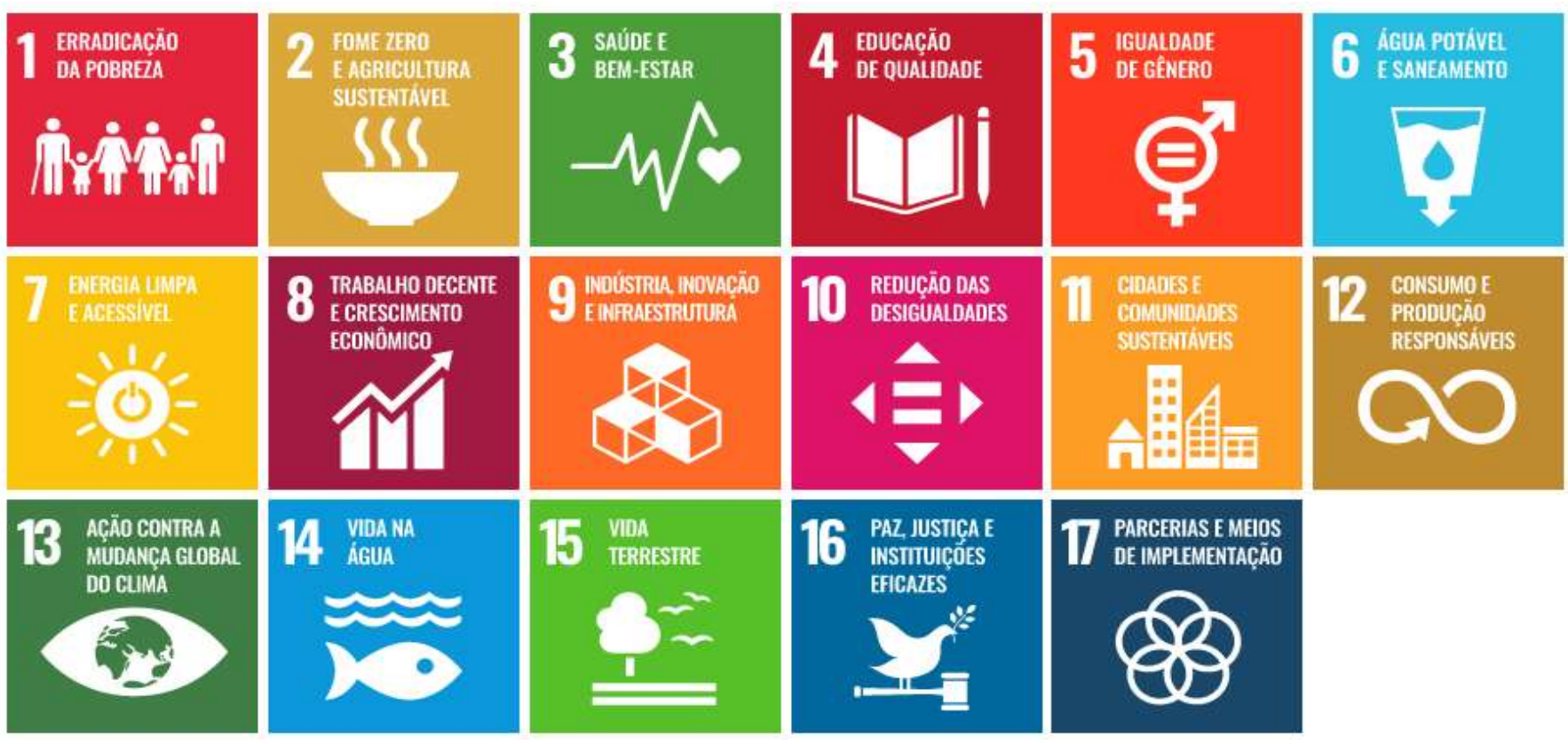

Fonte: Nações Unidas no Brasil (2021). 
Para atender ao objetivo 4 da Agenda: "Assegurar a educação inclusiva e equitativa de qualidade, e promover oportunidades de aprendizagem ao longa da vida para todos" o texto da BNCC incorporou 10 competências gerais para a Educação Básica (Quadro 1):

Quadro 1. Competências Gerais da BNCC.

\begin{abstract}
1. Valorizar e utilizar os conhecimentos historicamente construídos sobre o mundo físico, social, cultural e digital para entender e explicar a realidade, continuar aprendendo e colaborar para a construção de uma sociedade justa, democrática e inclusiva.
\end{abstract}

2. Exercitar a curiosidade intelectual e recorrer à abordagem própria das ciências, incluindo a investigação, a reflexão, a análise crítica, a imaginação e a criatividade, para investigar causas, elaborar e testar hipóteses, formular e resolver problemas e criar soluções (inclusive tecnológicas) com base nos conhecimentos das diferentes áreas.

3. Valorizar e fruir as diversas manifestações artísticas e culturais, das locais às mundiais, e também participar de práticas diversificadas da produção artístico-cultural.

4. Utilizar diferentes linguagens - verbal (oral ou visual-motora, como Libras, e escrita), corporal, visual, sonora e digital -, bem como conhecimentos das linguagens artística, matemática e científica, para se expressar e partilhar informações, experiências, ideias e sentimentos em diferentes contextos e produzir sentidos que levem ao entendimento mútuo.

5. Compreender, utilizar e criar tecnologias digitais de informação e comunicação de forma crítica, significativa, reflexiva e ética nas diversas práticas sociais (incluindo as escolares) para se comunicar, acessar e disseminar informações, produzir conhecimentos, resolver problemas e exercer protagonismo e autoria na vida pessoal e coletiva

6. Valorizar a diversidade de saberes e vivências culturais e apropriar-se de conhecimentos e experiências que lhe possibilitem entender as relações próprias do mundo do trabalho e fazer escolhas alinhadas ao exercício da cidadania e ao seu projeto de vida, com liberdade, autonomia, consciência crítica e responsabilidade.

7. Argumentar com base em fatos, dados e informações confiáveis, para formular, negociar e defender ideias, pontos de vista e decisões comuns que respeitem e promovam os direitos humanos, a consciência socioambiental e o consumo responsável em âmbito local, regional e global, com posicionamento ético em relação ao cuidado de si mesmo, dos outros e do planeta.

8. Conhecer-se, apreciar-se e cuidar de sua saúde física e emocional, compreendendo-se na diversidade humana e reconhecendo suas emoções e as dos outros, com autocrítica e capacidade para lidar com elas.

9. Exercitar a empatia, o diálogo, a resolução de conflitos e a cooperação, fazendo-se respeitar e promovendo o respeito ao outro e aos direitos humanos, com acolhimento e valorização da diversidade de indivíduos e de grupos sociais, seus saberes, identidades, culturas e potencialidades, sem preconceitos de qualquer natureza.

10. Agir pessoal e coletivamente com autonomia, responsabilidade, flexibilidade, resiliência e determinação, tomando decisões com base em princípios éticos, democráticos, inclusivos, sustentáveis e solidários.

Fonte: Brasil (2020a).

Diante da forte e declarada influência dos Organismos e dos acordos internacionais nas políticas educacionais brasileiras (Amestoy, 2019), destacamos aqui, o alinhamento do Brasil a Agenda 2030 - momento histórico no qual o país retrocede a um currículo pautado em competências e habilidades, já presente na época dos Parâmetros Curriculares Nacionais (PCN), porém agora de uma forma mais homogênea, unificando os currículos tanto da educação básica quanto do ensino superior. De acordo com Amestoy, Rigue e Gonçalves (2021): 
Esse pode ser considerado um importante marco naquilo que conhecemos enquanto historicidade, pois, demarca pela primeira vez a emergência de uma égide mundial quanto a ações educacionais. A agenda global para a educação 2030 ratifica a crescente influência das organizações internacionais nas políticas educacionais (Amestoy; Rigue \& Gonçalves, 2021, p. 180).

A partir de uma análise das políticas educacionais brasileiras desde a Lei de Diretrizes e Bases da Educação Nacional (LDBEN - Lei 9.394/1996), os PCN (1997), as Diretrizes Curriculares Nacionais da Educação Básica (DCN/EB/ 2010) e no mais recente Plano Nacional de Educação (PNE/ 2014-2024) estabelecido pela Lei no 13.005/2014 é possível identificarmos a intenção da inserção de um currículo comum nacional.

O documento da Base, em seu contexto histórico, é resultado de diferentes propostas de padronização da educação brasileira. Começando o seu trajeto a partir da obrigatoriedade prevista desde a Constituição Federal (CF) (Brasil, 1988) a qual estabelece, no seu Artigo 210 que: "Serão fixados conteúdos mínimos para o ensino fundamental, de maneira a assegurar formação básica comum e respeito aos valores culturais e artísticos, nacionais e regionais".

Historicamente, a partir da CF de 1988 e com a abertura política pós-ditadura militar, inicia o período de políticas neoliberais no país na chamada 'Era dos Fernandos' - Fernando Collor de Mello e Fernando Henrique Cardoso (FHC). E é a partir da década de 1990 que se intensificam políticas públicas educacionais com pautas dedicadas a diferentes tentativas de padronização/estandardização da educação brasileira.

Nesse viés, destacamos o artigo 26 da LDBEN/1996 o qual determina que:

os currículos da Educação Infantil, do Ensino Fundamental e do Ensino Médio devem ter uma base nacional comum, a ser complementada, em cada sistema de ensino e em cada estabelecimento escolar, por uma parte diversificada, exigida pelas características regionais e locais da sociedade, da cultura, da economia e dos educandos (Brasil, 1996).

Além desse destaque para a LDBEN, sinalizamos, também, a descrição textual de uma base comum a todas as localidades no texto constituinte do PNE (Brasil, 2014) como uma de suas metas. Assim, para atender a agenda global, cria-se uma agenda nacional com 20 metas programadas para a década (2014-2024). Em 2015, inicia-se o processo de construção da BNCC, sendo a mesma finalizada e homologada em 2017 para a Educação Infantil e o Ensino Fundamental e em 2018 para o Ensino Médio (Brasil, 2018b).

Destaca-se, que a BNCC apresenta-se como uma proposta de garantia de acesso a conhecimentos mínimos, que os estudantes têm o direito de estudar nos anos escolares. Todavia, vale ressaltar que a Base é uma das apostas do empresariado para crescimento econômico, de modo que o setor privado e também a sociedade civil (ONGs, institutos sem fins lucrativos e apartidários) realizaram grande movimento de propagação e legitimação de um discurso empresarial, transvestido de filantrópico em torno da educação brasileira.

Compreendida por diversos autores e pesquisadores da área de Ensino/Educação como uma arena de disputas, tanto política quanto de poder, o processo de construção da BNCC desenvolveu-se em um turbulento contexto histórico-político do país, considerando aqui tanto as alterações realizadas dentro do Ministério da Educação (MEC) quanto do contexto mais geral de crise política e econômica nacional.

O Todos pela Educação (TPE) e o chamado Movimento pela Base, são exemplos de grupos representantes da sociedade civil que vem desempenhando papel decisivo na legitimação da BNCC. Ambos, promoveram um slogan de 'educação de qualidade' e 'equidade', levantando uma pauta muito forte que arrastou multidões a seu favor. Porém, a proposta da BNCC para uma educação de qualidade baseia-se em uma aprendizagem alicerçada no desenvolvimento de habilidades e competências, conceitos considerados ultrapassados, reducionistas e utilitaristas (Martins, 2016; Branco; Branco; Iwasse \& Zanatta, 2018). 
O processo de construção da Base perdurou por cerca de três anos (2015-2018) e resultou em cinco versões diferentes, as quais foram marcadas por ferrenhas disputas de poder (Mattos; Tolentino-Neto \& Amestoy, 2021). Do ponto de vista das teorias críticas de currículo, Arroyo (2013) nos leva a entender que não há como dissociar o fato da seleção e do privilégio de determinados conhecimentos em relação a outros, com verdadeiras disputas políticas e ideológicas. Disputas essas, que tornam o currículo um solo fértil de persuasão e controle, constituindo-se um campo de disputa de interesses e ideias entre grupos dominantes.

Todavia em uma perspectiva pós-crítica o currículo não só tem efeitos, como sofre efeitos, portanto embora ele seja influenciado por mecanismos de mercado, que, cada vez mais, potencializam a lógica empresarial, produzindo valores de competitividade, de meritocracia e de privatização, ele ainda produz de certo modo esses conhecimentos por meio da relação poder-saber (Silva, 2009; Laval, 2019).

O discurso dominante interpela os sujeitos a tornarem-se favoráveis à necessidade da mudança, muitas vezes sem a reflexão crítica a respeito dos interesses latentes. Ademais, a Base não busca apenas padronizar o currículo, mas tem avançado sob uma série de políticas educacionais, gerando um alinhamento notável das políticas dos livros didáticos, das avaliações, das formações, entre outras. Tanto que com essa nova demanda formativa para a Educação Básica, foi homologada a Base Nacional Comum para a Formação Inicial de Professores da Educação Básica (BNC-Formação) (Brasil, 2019) e a Base Nacional Comum para a Formação Continuada de Professores da Educação Básica (BNC-Formação Continuada) (Brasil, 2020b).

Além disso, esse progressivo alinhamento prevê a elaboração de novos currículos à luz da BNCC, uma vez que a mesma conta com uma parte diversificada obrigatória. A parte diversificada da Base deve ser elaborada por sistemas, redes e também na escola, sendo que esses currículos devem contemplar conteúdos complementares a Base e específicos da realidade regional e/ou local (Brasil, 2018b).

É nesse contexto de elaboração da parte diversificada do documento da Base, que essa escrita se insere. Com a homologação da versão final da BNCC para o Ensino Fundamental em 2017, foi estabelecido o Programa de Apoio à Implementação da Base Nacional Comum Curricular (ProBNCC), por meio da Portaria MEC n 331/2018, visando auxiliar os estados e municípios na construção de seus próprios currículos a partir da BNCC (Brasil, 2018a).

A parte diversificada da Base, materializou-se com a responsabilização das secretarias estaduais e seguidamente municipais de construção desses documentos regionais/territoriais. No estado do Rio Grande do Sul (RS) foi construído o Referencial Curricular Gaúcho (RCG) que, durante o seu breve prazo de construção, disponibilizou uma plataforma virtual para contribuições, sendo que "a ferramenta possibilitou duas consultas públicas aos profissionais da educação [...] tais contribuições foram sistematizadas pelos Redatores de Currículo (SEDUC e UNDIME), acompanhados pelas Coordenadoras Estaduais de Currículo e as Coordenadoras de Etapa” (Rio Grande do Sul, 2018, p. 17).

Aprovado e homologado em dezembro de 2018, o RCG está organizado em seis cadernos o "primeiro que reúne princípios orientadores, concepções, tempos e espaços do currículo na Educação Infantil. Os demais organizados por Áreas do Conhecimento: Linguagens, Matemática, Ciências da Natureza, Ciências Humanas e Ensino Religioso" (Rio Grande do Sul, 2018, p. 17), levando em consideração o objetivo de contemplar aspectos pontuais do território do Rio Grande do Sul, podendo acrescentar ou não às habilidades da BNCC algo específico do Estado.

Da mesma maneira Santa Maria (SM), município da região central do RS, em específico a Secretaria de Município da Educação (SMED), recebeu a incumbência de construir o Documento Orientador Municipal (DOM) em 2019, visando atender as especificidades territoriais. O município de SM faz parte da $8^{\text {a }}$ Coordenadoria Regional de Educação de Santa Maria (CRESM) que abrange 23 municípios da região, atendendo um total de 103 escolas, com cerca de 33,5 mil estudantes (Rio Grande do Sul, 2021). 
Figura 2. Localização do município de Santa Maria, entre os municípios que compõem a $8^{\text {a }}$ Coordenadoria Regional de Educação (CRE).

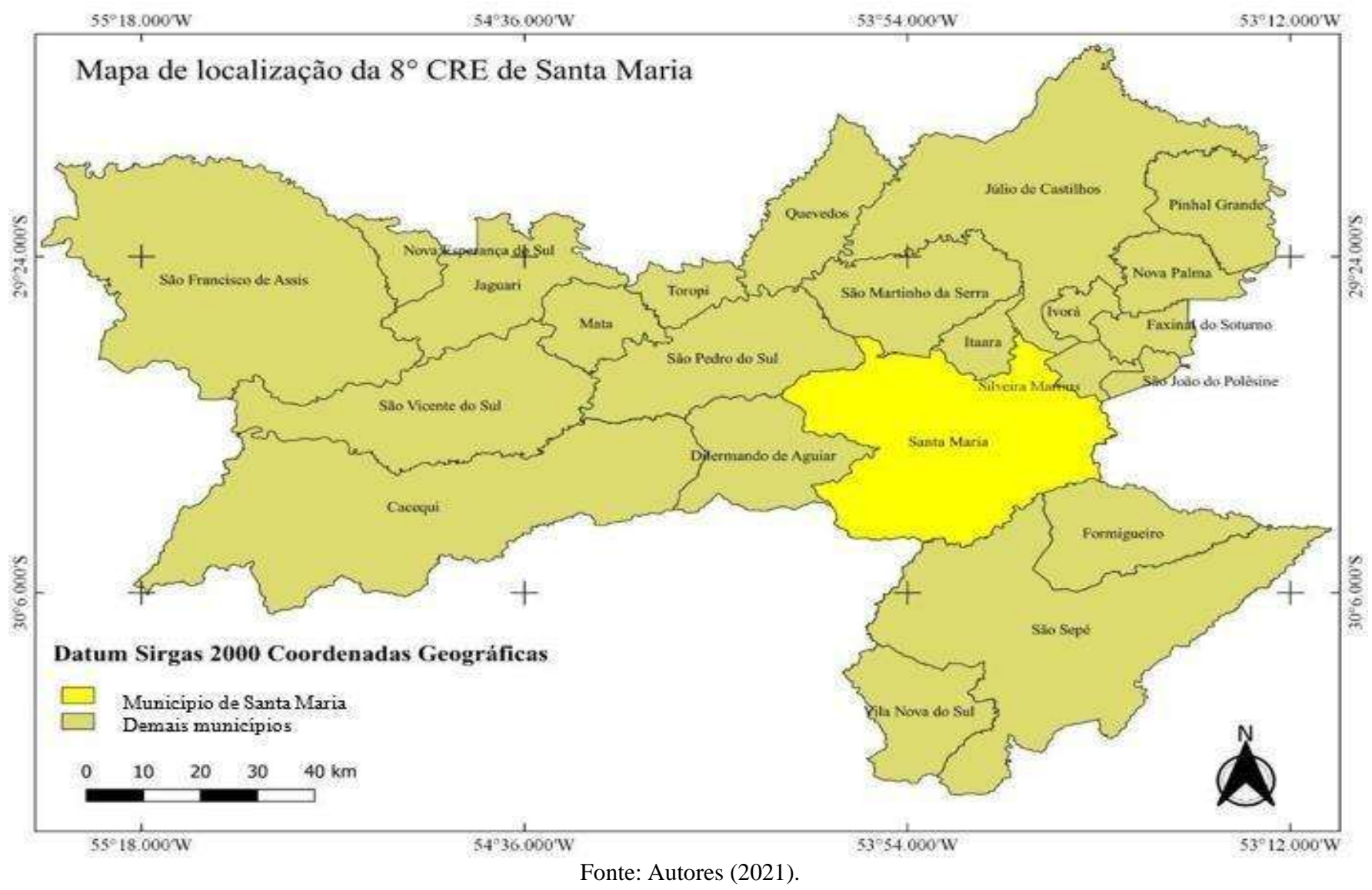

O município também faz parte dos 33 municípios que compõem a Associação dos Municípios da Região Central do Estado (AMCENTRO), regionais da União dos Dirigentes Municipais de Educação (UNDIME). Santa Maria tem, aproximadamente, 173 instituições de educação básica na esfera estadual, municipal, federal e privada, atendendo, aproximadamente, 58.113 alunos, distribuídos entre as diferentes redes de ensino disponíveis (Rio Grande do Sul, 2021). Por ter um sistema educacional grande em relação aos demais municípios pertencentes a $8^{\text {a }}$ CRE e a AMCENTRO, SM acabou por influenciar os demais municípios em relação ao movimento de elaboração do DOM.

Os direcionamentos dados às secretarias municipais pela CONSED e pela UNDIME, contavam com prazos limitantes e a importância de que houvesse engajamento de todas as redes de ensino presentes no município. Isso porque, uma vez construído e homologado, a utilização do DOM se tornaria obrigatória em todas as redes da educação básica do território, independentemente de sua participação ou não na elaboração da política municipal.

Diante desses encaminhamentos, o presente texto visa discorrer sobre o processo de construção do documento orientador de Santa Maria/RS, denominado posteriormente pelas comissões como DOC/SM. Assim, esse trabalho tem como objetivo apresentar apontamentos a respeito do processo de elaboração de uma política municipal, que teve como incumbência alinhar-se às outras duas políticas de currículo em curso - currículo nacional (BNCC) e o currículo estadual (RCG).

\section{Metodologia}

Essa escrita trata-se de um recorte de uma pesquisa em andamento, a qual se encontra vinculada a um projeto em um nível superior, revisado e aprovado, pelo Comitê de Ética em Pesquisa com Seres Humanos (CEP) da UFSM com o número de 
registro CAAE 29692620.4.0000.5346. Quanto à abordagem, a pesquisa caracteriza-se como qualitativa, com estudo de campo e coleta de dados por meio da observação participante (Gil, 2002).

O estudo de campo foi realizado para a investigação do grupo que compôs as comissões de articulação e sistematização do DOC/SM. Este procedimento permite a interação entre seus componentes, pois como o pesquisador realiza todo o trabalho presencialmente, ele se insere na comunidade de forma que os integrantes se sentem à vontade, utiliza-se mais a observação do que a interrogação. É um estudo com maior flexibilidade, mas procura manter o foco no aprofundamento das questões colocadas para o grupo. $\mathrm{O}$ fato de o pesquisador ir até o ambiente em que o fenômeno estudado acontece, garante maior fidedignidade à pesquisa (Gil, 2002).

A observação participante decorreu do momento da construção do DOC/SM, dos encontros e das audiências os quais foram acompanhados por meio desta técnica de coleta de dados, em que o "pesquisador busca estar ao lado do participante, compartilhando suas experiências [...] vivencia na medida do possível, as atividades, os interesses, os afetos e as ocasiões [...] de um grupo de participantes" (Ribeiro \& Gessinger, 2018, p. 99). Visando a democratização do processo, a SMED enviou convite aos professores de todas as áreas e redes (Privada, Municipal, Estadual e Federal) do município. A construção do DOC/SM chegou ao conhecimento da pesquisadora que pode inserir-se nas comissões de elaboração. Portanto, essa inserção ocorreu de forma artificial, pois a pesquisadora não fazia parte essencialmente do grupo, mas integrou-se a ele para a obtenção de dados (Lüdke \& André, 2013; Gil, 2007; Ribeiro \& Gessinger, 2018).

A elaboração do documento teve início quando os convidados aceitaram participar. A partir de então, foi composta uma comissão sistematizadora, organizada em encontros e audiências para apreciação pública do que fora decidido em grupos menores. Além da observação, foram realizadas anotações de campo de modo a sistematizar os principais apontamentos dos encontros e audiências. Considerando os cinco meses, tempo destinado para que o documento local fosse elaborado, será dada ênfase a dois aspectos controversos e notáveis desse processo: a democratização almejada pelos municípios e as amarras contidas nas entrelinhas da BNCC.

\section{Resultados e Discussão}

A Comissão Sistematizadora do DOC/SM foi constituída por um grupo diversificado de professores e gestores oriundos de diferentes redes de ensino e áreas do conhecimento, bem como por representantes do Conselho Municipal de Educação (CME) e sindicatos. No quadro a seguir, consta a sistematização do processo de construção do documento que ocorreu em 5 encontros iniciais, 12 audiências públicas e 2 encontros finais.

Quadro 2. Sistematização dos diferentes momentos da construção do DOC/SM

\begin{tabular}{|c|c|c|c|c|c|l|}
\hline \multicolumn{2}{|c|}{ Natureza } & Data & Turno & Local & Nível de ensino & \multicolumn{1}{|c|}{ Pauta } \\
\hline $1^{\circ}$ & Encontro & $10 / 07 / 19$ & Manhã & SMEd & Todos & $\begin{array}{l}\text { Apresentação sobre a BNCC e } \\
\text { proposta para a } \\
\text { construção do DOC/SM }\end{array}$ \\
\hline $2^{\text {o }}$ & Encontro & $22 / 07 / 19$ & Manhã & SMEd & Todos & $\begin{array}{l}\text { Retomada da proposta e } \\
\text { organização de discussão em } \\
\text { grupos, por área. }\end{array}$ \\
\hline $3^{\text {o }}$ & Encontro & $31 / 07 / 19$ & Tarde & SMEd & Todos & $\begin{array}{l}\text { Reunião particular da comissão } \\
\text { de Ciências. Sistematização e } \\
\text { formatação das contribuições. }\end{array}$ \\
\hline
\end{tabular}




\begin{tabular}{|c|c|c|c|c|c|c|}
\hline $4^{\circ}$ & Encontro & $09 / 08 / 19$ & Manhã & SMEd & Todos & $\begin{array}{l}\text { Leitura dos textos introdutórios } \\
\text { / organização para } 1^{\mathrm{a}} \text { audiência } \\
(\mathrm{NOME} \mathrm{DOC/SM)}\end{array}$ \\
\hline $5^{\circ}$ & Encontro & $16 / 08 / 19$ & Tarde & SMEd & Todos & $\begin{array}{l}\text { Leitura dos textos introdutórios } \\
\text { e dos conteúdos / organização } \\
\text { para } 1^{a} \text { audiência. }\end{array}$ \\
\hline $1^{\mathrm{a}}$ & $\begin{array}{c}\text { Audiência } \\
\text { Pública }\end{array}$ & $23 / 08 / 19$ & Manhã e tarde & IFFAR & $\mathrm{AF}$ & Textos introdutórios \\
\hline $2^{\mathrm{a}}$ & $\begin{array}{c}\text { Audiência } \\
\text { Pública }\end{array}$ & $28 / 08 / 19$ & Manhã e tarde & APUSM & $\mathrm{AF}$ & Conteúdos \\
\hline $3^{a}$ & $\begin{array}{l}\text { Audiência } \\
\text { Pública }\end{array}$ & $30 / 08 / 19$ & Tarde & APUSM & $\overline{\mathrm{AF}}$ & $\begin{array}{l}\text { Conteúdos e aprovação da área } \\
\text { de Ciências da Natureza }\end{array}$ \\
\hline $4^{\mathrm{a}}$ & $\begin{array}{l}\text { Audiência } \\
\text { Pública }\end{array}$ & $02 / 09 / 19$ & Manhã e tarde & SMEd & $\mathrm{AF}$ & $\begin{array}{l}\text { Término e aprovação dos Anos } \\
\text { Finais. }\end{array}$ \\
\hline $5^{\mathrm{a}}$ & $\begin{array}{l}\text { Audiência } \\
\text { Pública }\end{array}$ & $26 / 09 / 19$ & Manhã e tarde & IFFAR & EI & Textos introdutórios \\
\hline $6^{\mathrm{a}}$ & $\begin{array}{l}\text { Audiência } \\
\text { Pública }\end{array}$ & $27 / 09 / 19$ & Manhã e tarde & IFFAR & EI & Conteúdos \\
\hline $7^{\mathrm{a}}$ & $\begin{array}{l}\text { Audiência } \\
\text { Pública }\end{array}$ & $01 / 10 / 19$ & Manhã e tarde & IFFAR & EI e AI & Conteúdos \\
\hline $8^{a}$ & $\begin{array}{l}\text { Audiência } \\
\text { Pública }\end{array}$ & $02 / 10 / 19$ & Manhã e tarde & APUSM & AI & Conteúdos \\
\hline $9^{a}$ & $\begin{array}{l}\text { Audiência } \\
\text { Pública }\end{array}$ & $07 / 10 / 19$ & Manhã & IFFAR & AI & Conteúdos \\
\hline $10^{\mathrm{a}}$ & $\begin{array}{l}\text { Audiência } \\
\text { Pública }\end{array}$ & $11 / 10 / 19$ & Manhã e tarde & IFFAR & AI & Conteúdos \\
\hline $11^{\mathrm{a}}$ & $\begin{array}{l}\text { Audiência } \\
\text { Pública }\end{array}$ & $18 / 10 / 19$ & Manhã e tarde & $\mathrm{BM}$ & AI & Conteúdos \\
\hline $12^{\mathrm{a}}$ & $\begin{array}{l}\text { Audiência } \\
\text { Pública }\end{array}$ & $24 / 10 / 19$ & Manhã & $\mathrm{BM}$ & $\overline{\mathrm{AI}}$ & $\begin{array}{l}\text { Término e aprovação dos Anos } \\
\text { Iniciais }\end{array}$ \\
\hline $6^{\circ}$ & Encontro & $22 / 11 / 19$ & Manhã & SMEd & Todos & $\begin{array}{l}\text { Possibilidade de adequação do } \\
\text { DOC/SM à Agenda } 2030\end{array}$ \\
\hline $7^{\circ}$ & Encontro & $02 / 12 / 19$ & Tarde & SMEd & Todos & $\begin{array}{l}\text { Decisão de adicionar a Agenda } \\
2030 \text { no texto introdutório do } \\
\text { DOC/SM }\end{array}$ \\
\hline
\end{tabular}

Legenda: SMEd: Secretaria Municipal da Educação; APUSM: Associação dos Professores Universitários de Santa Maria; IFFAR: Instituto Federal de Educação Ciência e Tecnologia Farroupilha; BM: Biblioteca Municipal; AF: Anos Finais; EI: Educação Infantil; AI: Anos Iniciais. Fonte: Autores (2021).

Optou-se pela apresentação do quadro, pois o mesmo demonstra um panorama geral da construção, sendo que cada encontro e/ou audiência em específico possui diversos pontos relevantes em relação às impressões da comissão sobre essa 
proposta curricular (DOC/SM). Porém, uma análise mais refinada do processo ultrapassa o escopo dessa escrita, que se limitará em descrever o processo geral de elaboração do documento, questionando-se: o que foi mais expressivo ao longo dos quase 100 dias de construção do DOC/SM. A democratização desse processo sem dúvidas é a primeira resposta dessa pergunta, em contrapartida o segundo aspecto mais expressivo é a própria falta de autonomia, devido ao controle imposto pela BNCC.

A democratização aconteceu antes e durante o processo de elaboração do DOC/SM, com o envio prévio de convite de participação a todas as redes de ensino e para representantes de todas as áreas do conhecimento. O processo de construção do currículo municipal de Santa Maria ocorreu de forma democrática desde o primeiro ao último encontro, com audiências públicas permeando todo o processo.

É preciso compreender que muitos professores chegaram aos primeiros encontros sem conhecer a Base e o RCG. Houve muito comprometimento da comissão sistematizadora em realizar uma explanação do que se tratava a BNCC, sua organização em competências e habilidades e a ideia de aprendizagem em espiral.

A comissão disponibilizou um tempo para que os professores buscassem conhecer a Base, visto que essa era uma etapa fundamental. Nos encontros seguintes, em um entendimento a priori, os professores questionaram a possibilidade de alterações na BNCC a partir do DOC/SM. A comissão sistematizadora foi firme ao declarar que o processo de elaboração do DOC/SM, destinava-se apenas em incluir/adicionar habilidades específicas do território de Santa Maria (SM). Não se tratava de retirar/modificar as habilidades já estabelecidas pelo documento da Base e pelo documento estadual (RCG), de modo que esses documentos precisavam ser estudados e conhecidos para que não houvesse repetição de habilidades.

Adentramos aqui, nas questões relacionadas à autonomia de elaboração de políticas municipais. Embora os reconhecidos esforços da SMED para que a democratização do processo de construção curricular ocorresse os participantes não estavam livres nesse processo, eles estavam amarrados ao que o documento da BNCC já havia estabelecido. É válido resgatar que quando se trata de processo de democratização, incomoda o fato de não ter havido transparência a respeito do destino dado às mais de 12 milhões de contribuições para a BNCC, recebidas via consulta pública. Não houve evidências de qual (is) critério (s) de escolha (a) foi (foram) utilizado (s) e nem mesmo se alguma dessas contribuições foi inserida na última versão da Base. De todo modo, mesmo não sendo 'transparentes' os encaminhamentos dados, a BNCC foi homologada e segue como referencial para os demais currículos brasileiros (Brasil, 2016; Micarello, 2016; Oliveira, 2018).

Assim como o RCG partiu das habilidades propostas pela BNCC em sua construção, da mesma forma o DOC/SM baseou-se na BNCC e posteriormente no RCG. O alinhamento notável e limitante levou a comissão a organizar um documento único para que o professor tivesse acesso a BNCC, ao RCG e ao DOC/SM em um mesmo arquivo'. Quando se fala em amarras, refere-se ao engessamento causado pela BNCC. Como a parte diversificada será realmente um momento de autonomia se está totalmente condicionada aos moldes da Base? Como o professor dará a devida relevância aos conteúdos locais, se os conteúdos nacionais e estaduais por si só demandam uma carga horária exorbitante? Pode haver autonomia mesmo diante da obrigatoriedade? A SMED precisou mobilizar-se de forma rápida para elaboração do documento, pois o município poderia sofrer sanções/penalidades como, por exemplo, não receber o repasse de algumas verbas federais, caso não realizasse as adequações curriculares solicitadas.

Curiosamente a autonomia cedida aos sistemas, redes e escolas em nenhum momento pode afastar-se das competências estabelecidas pela Base. Seria essa uma autonomia real? Mesmo que os professores tenham realizado um árduo trabalho, como ocorreu em Santa Maria, haverá tempo para contemplação de todas competências da parte comum e ainda das elencadas na parte diversificada? Todos os currículos estão atrelados à Base, mais do que isso, eles a cumprirão integralmente,

${ }^{1}$ Link de acesso ao DOC/SM https://www.santamaria.rs.gov.br/smed/710-documentos. 
ainda que os professores optem por utilizar o DOC/SM, estarão utilizando a Base, pois todas as suas competências e habilidades estão presentes nesses documentos municipais. Essa é a essência da 'autonomia' designada aos sistemas, redes e professores, uma 'pseudoautonomia' que não deixa de exercer controle ao chamar os sujeitos ao protagonismo.

\section{Considerações Finais}

Por meio da observação participante, foi possível acompanhar e compreender não apenas a dinâmica de construção de um documento curricular municipal, mas também as tensões em torno das políticas públicas educacionais, percebendo como essas alterações são recebidas pelos professores da rede básica de ensino. Mesmo com as limitações, a comissão sistematizadora encarou o DOC/SM como uma oportunidade de inserir a contextualização local/territorial, não contemplada na Base. Ademais, destaca-se a cautela e a preocupação da comissão em manter o ritmo sem perder os prazos, promovendo um processo transparente e fluido. Concentrando as contribuições e tomando decisões de acordo com a manifestação da maioria.

Contudo, percebe-se uma barreira de contenção para a inserção dos conhecimentos legítimos do contexto local, acabando por prevalecer os conhecimentos selecionados como genéricos, para todo o contexto nacional. De todo modo, os encontros e audiências promoveram diversos momentos de aprendizagem conjunta, não só a respeito de currículo, mas de metodologias, avaliação, formação, entre outros. Formou-se uma rede de trocas de conhecimentos em diferentes áreas e níveis de ensino. Espera-se que mesmo diante desse efeito cascata de regulação, a parte diversificada possa ganhar maior robustez nos Projetos Políticos Pedagógicos (PPP) das escolas e nos próprios planos de aulas dos professores, de modo que os estudantes não vivam uma total desapropriação da sua realidade.

A pesquisa desenvolvida em torno do DOC/SM segue em andamento e tem acompanhado diversos reflexos da BNCC em contextos locais/territoriais. Almeja-se que este estudo instigue novas discussões e reflexões acerca das políticas públicas que moldam o currículo escolar. Sugere-se que as pesquisas futuras desenvolvidas nesse âmbito, possam demonstrar a regulação e verticalização das políticas educacionais, além de reforçar a relevância da voz do professor desde a gênese dessas políticas, até que isso seja uma realidade e não uma utopia.

\section{Agradecimentos}

À Universidade Federal de Santa Maria (UFSM), ao Programa de Pós-graduação em Educação em Ciências: Química da Vida e Saúde (PPGECQVS) e à Coordenação de Aperfeiçoamento de Pessoal de Nível Superior (CAPES).

\section{Referências}

Amestoy, M. B. (2019). A política de accountability na educação básica e os efeitos da avaliação externa no ensino e na gestão escolar: um estudo no município de Santa Maria/RS. (Tese de Doutorado, Universidade Federal de Santa Maria, Programa de Pós-graduação Educação em Ciências). https://repositorio.ufsm.br/bitstream/handle/1/19401/TES_PPGECQVS_2019_AMESTOY_MICHELI.pdf?sequence=1\&isAllowed=y.

Arroyo, M. G. (2013). Currículo, território em disputa. (5a ed.), Vozes.

Branco, E. P., Branco, A. B. G., Shalimar, C, Z., \& Nagashima, L. A. A implantação da Base Nacional Comum Curricular no contexto das políticas neoliberais. (1a ed.). Appris.

Brasil (1988). Constituição da República Federativa do Brasil de 1988. www.planalto.gov.br/ccivil_03/constituicao/ConstituicaoCompilado.htm. Acesso em: 10 mar. 2021.

Brasil (1996). Lei n. 9.394, de 20 de dezembro de 1996. Dispõe sobre as Diretrizes e Bases da Educação Nacional. http://www.planalto.gov.br/ccivil_03/leis/19394.htm.

Brasil (1998). Parâmetros Curriculares Nacionais: Terceiro e Quarto Ciclos do Ensino Fundamental: Introdução aos Parâmetros Curriculares Nacionais / Secretaria de Educação Fundamental. de http://portal.mec.gov.br/seb/arquivos/pdf/introducao.pdf.

Brasil. (2010). Resolução $n^{o}$ 04, de 13 de julho de 2010. Define Diretrizes Curriculares Nacionais Gerais para a Educação Básica. Recuperado de http://portal.mec.gov.br/dmdocuments/rceb004_10.pdf. 
Brasil (2013). Diretrizes Curriculares Nacionais da Educação Básica. http://portal.mec.gov.br/index.php?option=com_docman\&view=downl oad\&alias=15548- d-c-n-educacao-basica-nova-pdf\&Itemid=30192.

Brasil (2014). Lei $n^{o}$ 13.005, de 25 de junho de 2014. Aprova o Plano Nacional de Educação e dá outras providências. http://www.planalto.gov.br/ccivil_03/_ato2011-2014/2014/lei/113005.htm.

Brasil (2018a). Programa de Apoio à Implementação da BNCC -ProBNCC. https://www.gov.br/mec/pt-br/programas-e-acoes/programa-de-apoio-aimplementacao-da-base-nacional-comum-curricular-probncc.

Brasil (2018b). Base Nacional Comum Curricular: Educação é a Base. http://basenacionalcomum.mec.gov.br/images/BNCC_ EI_EF_110518_versaofinal_site.pdf.

Brasil (2019). Resolução $C N E / C P n^{o}$ 2, de 20 de dezembro de 2019. Define as Diretrizes Curriculares Nacionais para a Formação Inicial de Professores para a Educação Básica e institui a Base Nacional Comum para a Formação Inicial de Professores da Educação Básica (BNC- Formação). \&lt;http://portal.mec.gov.br/docman/dezembro-2019-pdf/135951-r-cp002-19/file\&gt;.

Brasil (2020a). Entenda como funciona a Base Nacional Comum Curricular. http://portal.mec.gov.br/component/content/article/211noticias/218175739/85151-entenda-como-funciona-a-base-nacional-comum-curricular?Itemid=164.

Brasil (2020b). Resolução $C N E / C P n^{\circ}$ 1, de 27 de outubro de 2020. Dispõe sobre as Diretrizes Curriculares Nacionais para a Formação Continuada de Professores da Educação Básica e institui a Base Nacional Comum para a Formação Continuada de Professores da Educação Básica (BNC-Formação Continuada). \&lt;https://www.in.gov.br/web/dou/-/resolucao- c-ne/cp-n-1-de-27-de-outubro-de-2020-285609724\&gt;

Gil, A. C. (2008). Como elaborar projetos de pesquisa. (4a ed.), Atlas.

Laval, C. (2019). A escola não é uma empresa: o neoliberalismo em ataque ao ensino público. (1a ed.), Boitempo.

Libâneo, J. C. (2016). Políticas educacionais no Brasil: desfiguramento da escola e do conhecimento escolar. Cadernos de Pesquisa, 46 (159), 38 -62. Recuperado de https://www.scielo.br/pdf/cp/v46n159/1980-5314-cp-46-159-00038.pdf.

Lüdke, M., \& André, M. E. D. A. (2013). Pesquisa em Educação: Abordagens Qualitativas. (2a ed.), EPU.

Martins, E. M. (2016). Todos pela educação? Como os empresários estão determinando a política educacional brasileira. (1a ed.), Lamparina.

Mattos, K. R. C., Toletino-Neto, L. C. B., \& Amestoy, M. B. (2021). Produção De Texto Da Base Nacional Comum Curricular E O Posicionamento Da Área Das Ciências Da Natureza. Revista Eletrônica Científica Ensino Interdisciplinar, $7 \quad$ (20), $266-281$. http://natal.uern.br/periodicos/index.php/RECEI/article/view/2836/2652.

Micarello, H. A. L. S. (2016). A BNCC no contexto de ameaças ao estado democrático de direito. Eccos - Rev. Cient., 1(41), 61-75. https://periodicos.uninove.br/eccos/article/view/6801/3429.

Moreira, A. F. B. (2012). O atual processo de internacionalização do campo do currículo: estratégias e desafios. Educação, Sociedade e Culturas, 1(37), 45-61. https://www.fpce.up.pt/ciie/sites/default/files/ESC37_A_Moreira.pdf.

Oliveira, I. B. (2018). Políticas Curriculares no Contexto do Golpe de 2016: Debates Atuais, Embates e Resistências. In: Aguiar, M. A. S., \& Dourado, L. F. (Org.). A BNCC na contramão do PNE 2014-2024: avaliação e perspectivas. avaliação e perspectivas. (Cap. 8, pp 55-59) ANPAE.

Nações Unidas Brasil (2021). Objetivos de Desenvolvimento Sustentável. https://brasil.un.org/pt-br/sdgs.

Ribeiro, A. P., \& Gessinger, R. M. (2018). Instrumentos de coletas de dados em pesquisas: questionamentos e reflexões. In: Lima, V. M. R, Harres, J. B. S., \& Paula, M. C. (Org.). Caminhos da pesquisa qualitativa no campo da educação em ciências: pressupostos, abordagens e possibilidades. (Cap. 4, pp 93-105) ediPUCRS

Rio Grande do Sul (2018). Referencial Curricular Gaúcho. Secretaria de Estado da Educação, Departamento Pedagógico. http://curriculo.educacao.rs.gov.br/Sobre/Index.

Rio Grande do Sul (2021). Coordenadorias Regionais de Educação. https://educacao.rs.gov.br/coordenadorias-regionais-de-educacao.

Silva, T. T. (2009). Documentos de Identidade: uma introdução às teorias do currículo. (3a ed.), Autêntica. 